DOI: 10.12957/demetra.2017.26799

\title{
Ambientes alimentares universitários: percepções de estudantes de Nutrição de uma instituição de ensino superior
}

\author{
Universities food environments: Nutrition student perceptions of a higher education institution
}

\author{
Mariana Cardozo de Oliveira' \\ Cláudia Roberta Bocca Santos' \\ Helena Silva do Nascimento? \\ Ionã Pereira Gomes dos Santos' \\ 1 Universidade Federal do Estado do Rio de \\ Janeiro, Escola de Nutrição. Rio de Janeiro-RJ, \\ Brasil. \\ Correspondência / Correspondence \\ Mariana Cardozo de Oliveira \\ E-mail: cardozo_mariana@live.com
}

\section{Resumo}

Objetivo: Analisar a percepção dos estudantes de Nutrição sobre o ambiente alimentar em uma instituição de ensino superior do Rio de Janeiro. Metodologia: Foi realizado um estudo qualitativo adotando grupos focais, sendo convidados estudantes de 18 a 30 anos dos cursos integral e noturno. Utilizou-se análise temática com categorias analíticas do material empírico: "caracterização do ambiente alimentar universitário", "o que é ambiente alimentar universitário?", "potencialidades e constrangimentos do ambiente alimentar universitário" e "o papel da instituição de ensino na promoção de um ambiente alimentar universitário saudável". Resultados: Participaram um total de 15 estudantes de graduação, de ambos os sexos, distribuídos em três grupos focais, com média de idade de 24 anos. A pesquisa refere-se ao período entre 2010 e 2015. Os participantes ressaltaram características do ambiente alimentar, indicando melhorias em relação à oferta de água potável e de opções de alimentação desde seu ingresso. Destacaram as opções de alimentação no entorno, ressaltando, no entanto, que são muito caras. O estudo não pretendeu analisar o ambiente alimentar universitário, mas apresenta uma breve caracterização do mesmo, no que tange à disponibilidade de alimentos, acessibilidade, variedade e custo. Discussão: Estudos revelam que o ambiente alimentar universitário ainda não é capaz de promover saúde, no que diz respeito à disponibilidade de alimentos adequados e saudáveis. O restaurante universitário é considerado um potencial promotor do acesso à alimentação adequada e salutar. Conclusões: Foi possível perceber a importância que o ambiente alimentar tem na determinação das práticas 
alimentares dos estudantes, podendo constranger ou favorecer práticas alimentares saudáveis.

Palavras-chave: Hábitos Alimentares. Comportamento Alimentar. Universidades.

\section{Abstract}

Objective: To analyze the perception of students of Nutrition on the food environment in a higher education institution of Rio de Janeiro. Methodology: A qualitative study was carried out adopting focal groups, where were invited students from 18 to 30 years of integral and nocturnal courses. Thematic analysis was used with analytical categories of the empirical material: "characterization of the university food environment", "what is a university food environment?", "potentialities and constraints of the university food environment" and "the role of the educational institution in promoting a healthy university food environment". Results: Fifteen undergraduate students of both sexes participated in three focus groups, with an average age of 24 years. The research refers to the period between 2010 and 2015. The participants highlighted characteristics of the food environment, indicating improvements regarding the supply of drinking water and food options since joining. They emphasize the options of feeding in the surroundings, highlighting, however, that they are very expensive. The study did not intend to analyze the university food environment, but presents a brief characterization of the same, regarding the availability of food, accessibility, variety and cost. Discussion: Studies show that the university food environment is not capable of promoting health in terms of the availability of adequate and healthy food yet. The university restaurant is considered a potential promoter of access to adequate and healthy food. Conclusion: It was possible to see the importance that the alimentary environment has in the determination of the feeding practices of the students, being able to constrain or favor healthy alimentary practices.

Keywords: Food Habits. Feeding Behavior. Universities. 


\section{Introdução}

A relação entre determinantes ambientais e desfechos nas práticas alimentares tem sido mais discutida na literatura na última década. ${ }^{1-6}$ Estudos têm buscado analisar aspectos relativos ao ambiente alimentar e sua influência nas práticas alimentares, como acessibilidade, disponibilidade, qualidade, variedade e custo dos alimentos. ${ }^{1-8}$ Glanz $^{9}$ destaca que a discussão sobre ambientes alimentares no âmbito da saúde pública é recente na literatura. A autora revela que ambientes organizacionais - como escolas, ambiente de trabalho, universidades, hospitais - podem desempenhar um papel ainda mais importante em relação à promoção de práticas alimentares saudáveis, quando comparados à prática regular de atividade física, visto que, em geral, tais ambientes possuem serviços de alimentação, mas não é comum espaços para a prática de atividades físicas.

Ao ingressar na universidade, muitos estudantes se deparam com a necessidade de responderem por si frente às demandas alimentares. A inexperiência para pensar sobre sua própria alimentação, associada ao estilo de vida, aos aspectos culturais, socioeconômicos e psicológicos, além de circunstâncias de natureza acadêmica, podem contribuir para escolhas alimentares inadequadas. ${ }^{10}$ Muitas vezes o próprio espaço universitário não proporciona um ambiente alimentar favorável ao consumo de alimentos considerados mais apropriados. ${ }^{11}$

No Brasil, as investigações sobre ambientes alimentares, em especial os organizacionais (como o espaço universitário), ainda são incipientes. Nesse contexto, o objetivo do presente estudo foi analisar a percepção de estudantes do Curso de Nutrição sobre o ambiente alimentar universitário de uma instituição pública federal de ensino superior do Estado do Rio de Janeiro.

\section{Métodos}

O projeto de pesquisa foi encaminhado ao Comitê de Ética em Pesquisa da Universidade Federal do Estado do Rio de Janeiro (CAAE: 43417115.6.0000.5285), sendo aprovado pelo Parecer $\mathrm{n}^{\circ} 1.071 .973$, no ano de 2015. Foi realizado um estudo qualitativo com realização de grupos focais. A unidade acadêmica lócus do estudo oferece dois cursos de graduação em Nutrição, ofertados no período integral e noturno.

Por meio de rede social, endereço eletrônico e cartazes afixados na instituição, foram convidados a participar todos os estudantes do curso, de ambos os sexos e com idades entre $18 \mathrm{e}$ 30 anos. A perspectiva era alcançar a pluralidade de composição dos grupos focais. Dessa forma, estimulou-se a participação de estudantes dos cursos integral e noturno, em função da hipótese de que os mesmos poderiam apresentar distintas percepções em relação ao ambiente alimentar universitário. Igualmente, buscou-se incentivar a participação de ingressantes e concluintes. A fim de contextualizar a fala dos estudantes, foram coletadas informações como idade, com quem 
mora (mora sozinho, com a família, entre outros), atividades desenvolvidas (se trabalha e estuda, se estuda e realiza estágio), curso (integral ou noturno), ano de ingresso na universidade e período atual do curso. O trabalho de campo foi realizado no período entre maio e junho de 2015.

A realização dos grupos focais adotou as orientações de Neto et al. ${ }^{12}$ e Minayo. ${ }^{13}$ Segundo Minayo, ${ }^{13}$ o grupo focal valoriza a interação entre os participantes e a construção coletiva de opiniões e argumentos. A técnica foi aplicada mediante um roteiro previamente planejado, em ambiente não diretivo, sob a coordenação de um moderador capaz de conseguir a participação de todos. O roteiro incluía questões sobre como os participantes se alimentavam quando estão na universidade, se levam alimentos e/ou preparações de casa ou se compram na universidade, se existem espaços para armazenarem a comida e se alimentarem na instituição, quais as opções de estabelecimentos que comercializam alimentos e/ou preparações, pontos positivos e negativos de se alimentar no campus, se existiram mudanças no ambiente alimentar desde o ingresso no curso, entre outras.

Além do moderador, outro pesquisador da equipe participou com o intuito de fazer um registro inicial das contribuições dos participantes. As contribuições foram gravadas em aparelho LG Optimus E989 e, posteriormente, transcritas para fins de análise pelas pesquisadoras, não havendo identificação de nenhum dos estudantes. Após a transcrição e revisão do material, foi realizada análise temática segundo Bardin, ${ }^{14}$ considerando categorias analíticas criadas a partir do material empírico, a saber: "caracterização do ambiente alimentar universitário", "o que é ambiente alimentar universitário?", "potencialidades e constrangimentos do ambiente alimentar universitário" e "o papel da instituição de ensino na promoção de um ambiente alimentar universitário saudável”.

\section{Resultados}

Foram realizados três grupos focais, de uma hora cada, com a participação de cinco alunos em cada um, sendo 12 do sexo feminino e três do masculino. Embora os grupos tenham sido realizados nos turnos vespertino e noturno a fim de proporcionar maior adesão, participaram apenas três estudantes do curso noturno. Entretanto, apesar dos estudantes majoritariamente matriculados no curso integral, todos já haviam cursado disciplinas nos cursos integral e noturno, vivenciando as possibilidades e os constrangimentos de se alimentarem no espaço universitário de cada turno. A média de idade foi de $24 \pm$ 1,2 anos. Apenas dois estudantes não estavam fazendo estágio no momento, o que denota que a maior parte de suas atividades é realizada no âmbito dos campi. Apesar de diferentes períodos, todos já estavam próximos de concluir o curso de Nutrição, sendo que 13 deles ingressaram na universidade em 2010. Portanto, a janela temporal do estudo se refere ao período de 2010 a 2015. Quase a metade dos estudantes (46,7\%) morava com pai e/ ou mãe, 20,0\% com outros familiares, 13,3\% com outros estudantes, 13,3\% moravam sozinhos e $6,7 \%$ moravam com amigos. 
A seguir, são apresentados os resultados relacionados às categorias analíticas, a saber: “caracterização do ambiente alimentar universitário", "o que é ambiente alimentar universitário?”, "potencialidades e constrangimentos do ambiente alimentar universitário" e o "papel da instituição de ensino na promoção de um ambiente alimentar universitário saudável”.

\section{Breve caracterização do ambiente alimentar universitário}

Considerou-se necessário caracterizar, ainda que de maneira incipiente, o ambiente alimentar ao qual os estudantes se referem. Não se pretendeu esgotar esta caracterização, mas oferecer um subsídio para a interpretação dos resultados, focalizando os locais que são utilizados pelos estudantes de Nutrição. A caracterização do ambiente alimentar institucional foi realizada com base em levantamento prévio efetuado por estudantes do curso de Nutrição e nos próprios grupos focais realizados nesta pesquisa.

A instituição lócus deste estudo é composta por sete campi, localizados de maneira dispersa pelo município do Rio de Janeiro, sendo três deles muito próximos entre si. Cada campus apresenta características distintas em relação ao ambiente alimentar universitário. Para fins deste estudo, serão descritos três campi específicos, escolhidos por serem frequentados por estudantes de Nutrição, e que caracterizaremos como campus A, B e C, assim nomeados a fim de não favorecer a identificação.

O campus A é o espaço no qual o estudante de Nutrição passa maior parte de sua formação. Atualmente, possui um restaurante comercial, com preço subsidiado para a comunidade acadêmica, que oferece pequenas e grandes refeições (estas últimas na modalidade self-service). Estão também disponíveis máquinas de venda de bebidas industrializadas, café e biscoitos. O serviço de reprografia também oferece algumas opções de lanches rápidos, geralmente confeccionados pelos próprios estudantes e disponibilizados para venda neste espaço. O prédio da Escola de Nutrição possui uma sala de convivência para os estudantes, na qual é possível armazenar, aquecer e realizar refeições. Cabe destacar ainda a proximidade deste campus ao de outra instituição de ensino superior, que oferece estabelecimentos para pequenas e grandes refeições, sendo comumente frequentada pelos estudantes de Nutrição. Embora não seja um local onde os estudantes da Nutrição possuem atividades acadêmicas, cabe indicar a proximidade do campus A com outros dois (um no qual foi posteriormente inaugurado o Restaurante Escola e o outro, com um trailer de lanches). Além disso, existem as opções de pontos comerciais no exterior dos campi, como shoppings, lojas de conveniência, entre outros.

a Levantamento realizado no âmbito das discussões do CALU - Grupo Colaborativo de Estudos sobre Ambiente Alimentar Universitário, coletivo criado em 2014 e composto por pesquisadores da UFRJ (campi Fundão e Macaé), UNIRIO, UFF e UERJ. Estudantes voluntários visitaram os campi da instituição a fim de identificar características principais dos estabelecimentos comerciais de alimentação de cada um. 
O campus B é o local onde os estudantes passam mais tempo no momento inicial do curso. Atualmente, existe um restaurante comercial do tipo self-service, que oferece pequenas e grandes refeições, além de pontos de venda de doces, biscoitos e bebidas. Este campus não possui um local de armazenamento para os estudantes que trazem refeições de casa, utiliza-se para tal microondas e geladeira de terceiros. Além disso, não há local para realizar as refeições. No entorno, há estabelecimentos comerciais e alguns restaurantes.

Já o campus C os alunos só frequentam para aulas práticas e para o estágio supervisionado em nutrição clínica. Possui um refeitório, contudo este só é permitido para acompanhantes, residentes e funcionários. Há local com uma geladeira, onde é possível armazenar a refeição. Também há um micro-ondas, que os alunos podem utilizar, contudo pertence a outro curso de graduação, segundo os relatos dos grupos focais. No entorno, há diversos tipos de restaurantes, além de estabelecimentos comerciais que servem refeições, supermercado, lanchonetes e padarias.

\section{O que é ambiente alimentar universitário?}

Quando questionados sobre o que compreendiam sobre a expressão ambiente alimentar universitário, a maioria dos estudantes sinalizou a disponibilidade física de alimentos em qualquer espaço no qual é possível adquirir alimentos e/ou realizar refeições, e que seja de fácil acesso a partir da localização da universidade, não se limitando ao campus universitário, como pode ser percebido no trecho abaixo.

Aquilo que está em volta. A gente vai usufruir daquilo que está ao redor da gente. Se pensar no campus do nosso prédio, só tem uma opção, tirando a xérox com os bolinhos e doces. Mas se você abrange isso [referindo-se ao que está em volta], aí você já vai ter a universidade ao lado, que tem mais opções, ou o shopping. Fora isso você tem que andar um pouco mais, então acaba saindo do raio confortável (Estudante 7, grifos nossos).

Ou seja, identificaram que o entorno compõe o ambiente alimentar universitário, e não apenas os campi. Esta compreensão inicial foi sendo enriquecida pelos próprios estudantes, que elencaram outros fatores, como a ambiência dos espaços destinados às refeições, referindo-se à iluminação, às cores utilizadas no refeitório, aos odores, aos espaços disponíveis para realização de refeições, ao custo financeiro dos alimentos e à própria necessidade de implantação do restaurante universitário, e a possível ingerência da Escola de Nutrição da instituição.

\section{Potencialidades e constrangimentos do ambiente alimentar universitário}

Os estudantes revelaram ter uma alimentação não saudável, na visão deles, principalmente nas pequenas refeições, por consumirem elevadas quantidades de bebidas industrializadas, 
doces e biscoitos e em função da baixa oferta no espaço universitário de alimentos considerados salutares, como frutas.

Quando perguntados a respeito de fatores que constrangem as oportunidades para realizar uma alimentação saudável no espaço universitário, os estudantes sugeriram alterações nas opções de alimentos e preparações, especialmente nas pequenas refeições. As propostas são de inclusão de sucos de frutas, leite batido com frutas e saladas de frutas nos lanches, além da cobrança em relação à inauguração do Restaurante Escola, que foi posteriormente inaugurado de maneira definitiva após um curto período aberto. Os estudantes sinalizaram ainda que durante as férias e finais de semana, quando a disponibilidade de alimentos considerados saudáveis é maior, eles têm a oportunidade de fazer escolhas mais benéficas.

Eu também sempre achei pior a parte da tarde (...). Se eu quiser lanchar, ou eu vou comer salgado, ou eu vou comer salgado. Não tem opção, ou como sorvete ou um brownie, eu não tenho uma op̧̧ão (Estudante 7, grifos nossos).

As adversidades encontradas no período noturno foram mencionadas pelos estudantes em função da percepção da ausência de infraestrutura em relação à alimentação no início do curso. A sensação de falta de apoio ao curso noturno em relação às possibilidades de alimentação no campus foi muito marcante entre os estudantes. Eles relataram que máquinas de biscoito, café e bebidas industrializadas foram instaladas após reivindicações dos alunos, o que não resolve a questão do ponto de vista da disponibilidade de alimentos adequados e saudáveis. Diante destas sugestões, percebe-se que um elemento importante a ser aprimorado neste ambiente alimentar se refere à disponibilidade de alimentos, segundo os estudantes.

Chama a atenção o questionamento feito pelos estudantes quanto ao horário de oferta das disciplinas dos primeiros períodos que integram o curso, visto que precisam se deslocar entre os campi A e B para terem aulas e por vezes o período de tempo para isso (e ainda se alimentar) é muito curto.

No primeiro período, às segundas feiras a gente tinha uma aula (...) de 10 ao $12 \mathrm{~h}$ no campus A e uma aula às 13 h no campus B e o ônibus saía daqui às 12:20. E nem era aqui, saía do [outro campus localizado na mesma rua do campus A]. Ou seja, não dava tempo. A gente tinha que engolir alguma coisa, fora a fila que era para comer também, fila para esquentar no micro-ondas daqui, que só era um (Estudante 5, grifos nossos).

(...) eu lembro que no primeiro período quem é do integral, eu não sei se a grade ainda continua assim, mas a gente terminava a aula meio-dia aqui e uma hora tinha que estar no campus B. A gente tinha que se deslocar, aí assim, não dava para almoçar. Então todo dia no primeiro período às segundas era tipo um lanche, não sei se a grade continua assim. Ai a gente pedia para a professora liberar uns 15 minutos mais cedo para conseguir lanchar e acontece muito isso. Às vezes você chega e tem que almoçar na aula, tipo compra na cantina, bota na marmitinha da cantina e almoça na sala de aula (Estudante 4, grifos nossos). 
Como aspectos positivos do ambiente alimentar universitário, os estudantes relataram mudanças importantes desde que iniciaram o curso, em especial no campus A, como a reabertura da cantina existente neste local com um restaurante comercial de melhor qualidade que o anterior (segundo os relatos) e que fica aberto durante a noite, podendo beneficiar os estudantes do curso noturno. No campus B, os alunos relataram que havia uma cantina que fornecia refeições empratadas. Atualmente, o serviço é de self-service, onde os alunos relatam ter maior variedade e poder de escolha. No entanto, neste campus os estabelecimentos não permanecem abertos no turno noturno. Em ambos os campi (A e B), foram identificadas pelos próprios estudantes muitas mudanças, não só em relação às opções de alimentos e refeições, como no acesso à água potável (foram disponibilizadas mais fontes de água potável na instituição). Também foram citadas as melhorias que atingiram a sala dos alunos do campus A, visto que atualmente há mais equipamentos para aquecer as refeições.

\section{O papel da instituição de ensino na promoção de um ambiente alimentar universitário saudável}

Na visão dos estudantes, há a necessidade de aproximação da Escola de Nutrição com o Restaurante Escola, embora pareçam desconhecer que já havia, na época de realização desta pesquisa, uma docente da Escola de Nutrição cedida para atuar na gestão do Restaurante. Percebese pelas falas uma cobrança dos alunos em relação ao que consideram ser papel da unidade acadêmica na promoção de um ambiente alimentar saudável na universidade.

Sabe, vou comparar a Escola de Nutrição a um médico fumante, enquanto o paciente não pode fumar, não pode fumar. A Escola hoje funciona assim. (...) Não dá para dizer que o ambiente faz as pessoas na Escola de Nutrição, porque a gente não tem um ambiente adequado pra se alimentar (....). Como eu vou dizer 'quando for fazer a sua refeição, prefira ambiente silencioso' se a gente próprio não pratica aqui na universidade? (Estudante 10, grifos nossos).

(...) Toda hora que leio sobre uma reclamação do restaurante universitário, fico envergonhada. Porque a gente tem uma Escola de Nutrição aqui (Estudante 2, grifos nossos).

Os estudantes afirmam ainda a importância do Restaurante Escola como campo de projetos de ensino, pesquisa e extensão, destacando-o como um potencial campo de prática e local para estágio.

(...) não custava colocar a gente ali entendeu? A gente não faz estágio voluntário para restaurante privado? [possivelmente se referindo aos estágios obrigatórios] (...) É de graça, a gente faz estágio de graça para uma instituição privada, mas não fazemos de graça para ajudar a nossa (...) (Estudante 9, grifos nossos).

Poucos estudantes relataram já ter frequentado o Restaurante Escola. Um dos possíveis motivos é que muitos deles já estavam em períodos mais finais da grade curricular, frequentando menos o campus A, próximo ao local no qual o Restaurante Escola está alocado. 


\section{Discussão}

Para Zuccolotto, ${ }^{2}$ o conceito de ambiente alimentar envolve a dimensão do acesso aos alimentos, que incluiria a quantidade, o tipo, a localização, a acessibilidade ao comércio de alimentos e a dimensão da disponibilidade, onde se considera as características dos alimentos que são encontrados nestes locais, como o preço, a variedade e a qualidade.

Para contextualizar o ambiente alimentar e as questões que afetam as escolhas alimentares, Story et al. ${ }^{15}$ construíram um modelo teórico que indica diferentes níveis de intervenção para as políticas públicas, desde os fatores individuais até o nível macro. Os autores apontam que os fatores individuais incluem conhecimentos, comportamentos, fatores biológicos e demográficos, mas que, além destas questões, os ambientes social, físico e macro também influenciam as práticas alimentares. Dessa forma, as práticas alimentares não dependem exclusivamente de escolhas individuais, mas são afetadas por diversos fatores que escapam ao desejo ou à governabilidade do indivíduo.

No que tange ao ambiente social, os autores ${ }^{15}$ indicam que a interação com outras pessoas e a comunidade em que se vive poderia afetar as práticas alimentares em função de questões como apoio social e normas estabelecidas, por exemplo. Quanto ao ambiente físico, os autores citam os diversos espaços onde as pessoas se alimentam ou adquirem alimentos, que, por sua vez, determinam a disponibilidade de alimentos. Os autores sinalizam que, apesar da sua influência indireta, o ambiente em nível macro atinge fortemente o que as pessoas comem, como, por exemplo, políticas públicas que afetam o modo de produção, de distribuição e o preço dos alimentos.

Swinburn et al. ${ }^{16}$ também desenvolveram um modelo teórico para identificação de intervenções no ambiente, chamado ANGELO (Analysis Grid for Environments Linked to Obesity), que desdobra o ambiente em duas dimensões de acordo com seu tamanho (micro e macro) e tipos (físico, econômico, político e sociocultural). De acordo com as características do ambiente, ele pode ser reconhecido como ambiente obesogênico ou leptogênico, a depender dos fatores que influenciam o consumo alimentar e a prática de atividade física.

Alguns dos fatores sinalizados pelos estudantes ao longo dos grupos focais no presente estudo referem-se ao tipo físico do modelo analítico proposto pelos autores ${ }^{16}$ no qual os mesmos incluem "o que está disponível” em termos de alimentos, envolvendo não apenas o que está visível, como também fatores menos tangíveis, como o acesso à informação. Nesse modelo, o tipo econômico alude ao custo relacionado ao alimento, que está fortemente influenciado pelo custo da cadeia alimentar, e à renda nacional e individual. Quanto ao ambiente político, os autores referem-se às regras relacionadas à alimentação e à prática de atividade física, como leis, políticas públicas (formais e informais) e regras institucionais, como, por exemplo, escolas. Por fim, o ambiente sociocultural refere-se às atitudes, crenças e valores comunitários e/ou sociais relativos à alimentação e à atividade física. 
Entre as falas dos estudantes obtidas nos grupos focais deste estudo, foi possível perceber outros elementos relacionados ao ambiente alimentar universitário para além do ambiente físico, como propõe os autores. Por exemplo, questões relacionadas ao preço elevado dos alimentos/ refeições (econômico) e à implantação do restaurante universitário e o papel da Escola de Nutrição (político). Portanto, embora tenham inicialmente focalizado na disponibilidade de alimentos como um elemento que caracteriza o ambiente alimentar universitário, os estudantes puderam indicar outras questões que compõem tal arranjo conceitual.

Outro ponto importante a ser ressaltado diz respeito à visão dos estudantes sobre sua própria alimentação quando, majoritariamente, classificaram-na como não saudável. Esta visão demonstra a percepção dos estudantes do que é considerado alimento saudável e alimento não saudável, que pode ser fortemente orientada por uma perspectiva biomédica sobre a alimentação, e que Pollan ${ }^{17}$ caracterizaria pelo termo "nutricionismo", isto é, uma abordagem reducionista da alimentação com enfoque apenas no conteúdo calórico e nutricional dos alimentos. Esta visão acaba por polarizar os alimentos em alimentos saudáveis (e, portanto, permitidos) e alimentos não saudáveis (que seriam proibidos). Ratificada por uma vertente ainda hegemônica da ciência da Nutrição, esta visão pode ser ainda mais presente entre estudantes desta área de conhecimento.

No entanto, cabe aqui ressaltar que não foi o objetivo deste estudo aprofundar esta discussão entre os estudantes. Nesse sentido, discutir os sentidos do "comer saudável" e do comer "não saudável" na visão dos estudantes a partir dos grupos focais realizados neste estudo carece de elementos para que possamos determinar a influência da visão biomédica. Os mesmos podem ter adotado outros critérios para classificar a própria alimentação como não saudável, como, por exemplo, o fato de que os alimentos por eles citados são, geralmente, ultraprocessados, que trazem um impacto negativo não apenas à saúde humana como também ao meio ambiente. ${ }^{18}$

É também interessante sinalizar a falta de tempo, indicada pelos estudantes, para se alimentarem. Feitosa et al. ${ }^{19}$ analisaram os hábitos alimentares de 718 estudantes de diferentes cursos de graduação da Universidade Federal de Sergipe. Os resultados indicaram, entre outras questões, como hábito comum entre as mulheres a troca de refeições por lanches, justificado, segundo os estudantes, pela rotina universitária, que afetaria o tempo para se alimentar corretamente. ${ }^{19}$ Fonseca ${ }^{20}$ comenta que o ritmo de vida se modificou e que houve um reordenamento do tempo destinado às diferentes atividades, entre elas, a alimentação, o cozinhar, a comensalidade. Esta questão aparece claramente nos trechos destacados, nos quais os estudantes parecem considerar a alimentação como algo secundário ou que, diante dos compromissos mais "urgentes" e das dificuldades impostas pelo ambiente alimentar ("fila para comer", "fila para esquentar no microondas"), pode ser substituído ("engolir alguma coisa", "todo dia no primeiro período às segundas era tipo um lanche") ou adaptado ("bota na marmitinha da cantina e almoça na sala de aula”). 
Fitzgerald e Spaccarotella ${ }^{21}$ discutem as barreiras para adoção de um estilo de vida saudável, envolvendo a alimentação e a prática regular de atividade física. Para apresentar esses obstáculos, utilizaram um modelo ecológico dividindo-os em diferentes níveis, como intrapessoal, interpessoal, comunidade/institucional e macro/políticas públicas. No intrapessoal, o modelo indica as preferências, percepções, motivações, conhecimento, limitações socioeconômicas, entre outros fatores. No nível interpessoal, são considerados o apoio social, as questões culturais, disponibilidade de alimentos intradomiciliar, entre outros. Em relação ao plano comunitário/institucional, os autores indicam, por exemplo, o ambiente alimentar na escola, nos espaços de trabalho, características socioeconômicas, tamanho de porções de alimentos/preparações. Por fim, no nível macro, discutem as políticas públicas relacionadas à alimentação, preços dos alimentos, entre outros. Dessa forma, os autores $^{21}$ alertam que as escolhas alimentares e a prática regular de atividade física não dependem única e exclusivamente de fatores pessoais, como o desejo e a motivação.

Considerando as diferentes barreiras apontadas pelos autores, ${ }^{21}$ a promoção da alimentação saudável deve ser realizada por ações integradas de incentivo, apoio, proteção e monitoramento. As primeiras (que são usualmente alvo de profissionais de saúde) são aquelas que buscam estimular a adoção de práticas saudáveis pela população. No entanto, tem sido cada vez mais discutido na literatura acadêmica a importância de articular a estas ações medidas de apoio e de proteção, tendo em vista que as práticas alimentares são influenciadas por múltiplos determinantes que não exclusivamente o conhecimento sobre o valor nutricional dos alimentos. Nesse sentido, as medidas de apoio são aquelas que envolvem ações que buscam facilitar escolhas saudáveis em indivíduos já motivados. ${ }^{22}$ Por exemplo, considerando o objeto deste estudo, ou seja, o ambiente alimentar universitário, uma medida de apoio poderia ser a oferta de alimentos e refeições saudáveis em restaurantes comerciais e universitários ou ainda a disponibilização de infraestrutura para armazenamento e aquecimento de refeições trazidas de casa pelo estudante.

Muitas pesquisas envolvendo universitários limitam-se a avaliar seus hábitos alimentares e de prática de atividade física, composição corporal, estado de saúde, entre outros aspectos. ${ }^{10,19,23,24,25}$ Portanto, não foram encontrados na literatura acadêmica estudos que buscassem identificar a percepção de estudantes a respeito do ambiente alimentar universitário. No entanto, pesquisa realizada por Alves \& Boog, ${ }^{26}$ com o intuito de analisar aspectos subjetivos da alimentação de universitários residentes em moradia estudantil, traz contribuições importantes à discussão em questão. Para os autores, os estudantes demonstraram preocupação com o tornar-se provedor, ou seja, sobre o fato de passarem a assumir determinadas responsabilidades no autocuidado, como o preparo da própria alimentação. A comida de casa, preparada pela mãe principalmente, é tida como uma referência de alimentação saudável. Entre as dificuldades citadas no estudo para conseguirem se alimentar bem, os participantes elencaram tempo, dinheiro, falta de conhecimento sobre como preparar os alimentos e dificuldade de acesso a produtos. O restaurante universitário foi citado como essencial para que conseguissem se alimentar adequadamente. 
$\mathrm{Pulz}^{8}$ analisou o ambiente alimentar universitário de uma universidade pública do sul do Brasil. Diferentemente do ambiente alimentar universitário das lanchonetes, caracterizado pelos alunos participantes do presente estudo, a autora observou ampla variedade de alimentos e bebidas. Igualmente ao relatado pelos estudantes nos grupos focais, nenhuma das lanchonetes comercializava fruta in natura. Entretanto, a autora afirma que metade dos restaurantes analisados oferecia fruta in natura como sobremesa de forma gratuita. Em nossa investigação, tal aspecto se apresentou como umas das maiores reclamações feitas pelos alunos nos grupos focais, visto que relataram faltar opçóes mais saudáveis, como sucos, leite batido com frutas e frutas in natura ou salada de frutas.

A oferta de doces pagos separadamente e de frutas in natura sem custo adicional é vista por $\mathrm{Pulz}^{8}$ como uma forma de estimular o consumo de frutas. A autora acredita que a falta de frutas in natura nas lanchonetes é um fator limitante ao estímulo e ingestão de frutas no ambiente universitário. Como dito, muitos dos universitários passam o dia nesse ambiente e a ausência de oferta de alimentos mais saudáveis dificulta que estes indivíduos atinjam as recomendações de consumo propostas pela Organização Mundial de Saúde. Além disso, estes estudantes podem acabar optando por escolhas menos salutares, já que as mais saudáveis não estão disponíveis.

O Guia Alimentar para a população brasileira,${ }^{18}$ publicado em 2014, aborda a importância do consumo de alimentos in natura e minimamente processados e a redução da ingestão de ultraprocessados como um importante passo para a concretização de uma alimentação adequada e saudável. A inexistência de opções de sucos de frutas naturais ou em polpa e a ampla variedade de bebidas açucaradas, como refrigerantes, sucos em lata e refrescos prontos, sendo vendidas nas cantinas presentes nos campi frequentados pelos alunos de Nutrição, foram sinalizados como um dos pontos negativos no estudo de Pulz. ${ }^{8}$

Um dos pontos negativos citados pelos alunos nos grupos focais é o preço das refeições e o quanto é caro se alimentar fora de casa, especialmente considerando o entorno da instituição de ensino na qual foi realizado este estudo. Uma das opções de locais para se alimentar citada pelos estudantes é um shopping, que está localizado a poucos minutos de alguns campi.

Na visão de Pulz, ${ }^{8}$,a maior influência do ambiente sobre preferências alimentares é devido à grande limitação em termos de disponibilidade e acesso aos alimentos saudáveis e opções de qualidade com preços acessíveis, porque quando o ambiente alimentar é considerado impróprio, este pode desencorajar o consumo de frutas e hortaliças e aumentar o estímulo ao consumo de opções menos saudáveis. Pulz $z^{8}$ relacionou que alimentos com maior qualidade alimentar e nutricional possuíam preços mais altos quando comparados com as opções de menor qualidade. Os resultados encontrados pela autora em seu estudo sugerem que a qualidade da alimentação dos universitários pode estar sendo comprometida, pois se caracterizou um ambiente alimentar com limitações, como baixa oferta de produtos mais salutares, e entre os estudantes com limitações 
financeiras, este ambiente reduzia ainda mais as opções de escolha, tendo em vista que produtos de melhor qualidade nutricional tinham preços mais elevados.

O mesmo foi caracterizado pelos estudantes de Nutrição ouvidos neste estudo. Pelos seus relatos, os ambientes alimentares frequentados por eles não dispõem de alternativas mais saudáveis, variedade e alimentos de baixo custo. Para Glanz, ${ }^{7}$ o preço e a disponibilidade são os principais fatores do ambiente alimentar, sendo que o custo tem sido apontado como o segundo principal fator de decisão para as escolhas alimentares. Batalha et al. ${ }^{27}$ observam que o preço dos alimentos e o nível socioeconômico também influenciam as decisões de compra, entretanto, não devem ser consideradas como variáveis isoladas para uma interpretação do comportamento do consumidor.

\section{Conclusão}

Como limitações do presente estudo, cabe ressaltar que não houve participação de ingressantes como desejado. Além disso, a expectativa era de alcançar um maior número de estudantes nos grupos focais. Ainda que a adesão dos estudantes a esta pesquisa tenha sido insatisfatória, não foi considerada insuficiente, já que se percebeu a saturação das contribuições ao longo dos grupos focais.

Embora não tenha sido o objetivo deste estudo analisar a relação entre o ambiente alimentar universitário e as práticas alimentares dos estudantes, é importante destacar que após a realização desta pesquisa foi inaugurado o Restaurante Escola da universidade, com nutricionistas concursadas para acompanhar a rotina no dia a dia e a participação de docentes no grupo gestor, além de outros setores envolvidos.

A partir da caracterização dos estudantes de Nutrição, é possível identificar diversas barreiras que o ambiente alimentar universitário dos campi que estes alunos frequentam impõe em relação à possibilidade de alimentarem-se adequadamente, tanto no que diz respeito à acessibilidade, quanto à disponibilidade, qualidade, variedade, tempo adequado e custo financeiro dos alimentos e refeições. Os estudantes relatam que a indisponibilidade de opções saudáveis para consumo no ambiente universitário dificulta o aproveitamento desses alimentos. Embora o presente trabalho não tenha avaliado o consumo alimentar dos estudantes, os relatos sinalizam uma situação preocupante no que diz respeito ao consumo de bebidas industrializadas, doces e biscoitos, por exemplo. Estas escolhas alimentares inadequadas podem estar relacionadas ao desenvolvimento de algumas doenças, como obesidade, diabetes mellitus, hipertensão arterial sistêmica e até câncer.

Por fim, um ambiente alimentar universitário saudável é imprescindível para garantia do direito humano à alimentação apropriada por este grupo populacional, a fim de concretizar a Segurança Alimentar e Nutricional. Apesar de terem sido relatadas mudanças nesse ambiente alimentar ao longo do curso, com significativas melhorias, compreende-se que mudanças ainda 
são necessárias, agregando ações de incentivo, apoio, proteção e monitoramento da alimentação adequada e salutar no espaço universitário.

\section{Colaboradores}

Oliveira MC e Santos CRB participaram de todas as etapas de realização do trabalho, desde a concepção do desenho do estudo até a análise e divulgação dos resultados, incluindo a elaboração do manuscrito. do Nascimento HS e dos Santos IPG participaram do trabalho de campo, bem como da análise dos resultados e elaboração do manuscrito.

\section{Referências}

1. Duran ACFL. Ambiente alimentar urbano em São Paulo, Brasil: avaliação, desigualdades e associação com consumo alimentar [Tese]. [São Paulo]: Universidade de São Paulo, Faculdade de Saúde Pública; 2013.

2. Zuccolotto DCC. A relação entre percepção do ambiente alimentar e o consumo de frutas e hortaliças em gestantes [Dissertação]. [Ribeirão Preto]: Universidade de São Paulo, Faculdade de Saúde Pública; 2013.

3. Mendes LL. Ambiente construído e ambiente social: associação com o excesso de peso em adultos [Tese]. [Belo Horizonte]: Universidade Federal de Minas Gerais, Escola de Enfermagem de Minas Gerais; 2012.

4. Caspi CE, Sorensen G, Subramanian SV, Kawachi I. The local food environment and diet: a systematic review. Health Place 2012; 18(5):1172-1187.

5. Holsten JE. Obesity and the community food environment: a systematic review. Public Health Nutr. 2008; 12(3):397-405.

6. Perez PMP, Castro IRR, Franco AS, Bandoni DH, Wolkoff DB. Práticas alimentares de estudantes cotistas e não cotistas de uma universidade pública brasileira. Ciênc Saúde Coletiva 2016; 21(2):531-542.

7. Glanz K, Sallis JF, Saelens BE, Frank LD. Healthy nutrition environments: concepts and measures. Am J Health Promot. 2005; 19(5):330-333.

8. Pulz IS. Ambiente alimentar do campus sede da Universidade Federal de Santa Catarina [Dissertação]. [Florianópolis]: Universidade Federal de Santa Catarina, Programa de Pós Graduação em Nutrição; 2014.

9. Glanz K. Measuring food environments a historical perspective. Am J Prev Med. 2009; 36(4):93-98.

10. Petribú MMV, Cabral PC, Arruda IKG. Estado nutricional, consumo alimentar e risco cardiovascular: um estudo em universitários. Rev Nutr. 2009; 22(6):837-846.

11. Leite FHM, Oliveira MA, Cremm EC, Abreu DSC, Maron LR, Martins PA. Oferta de alimentos processados no entorno de escolas públicas em área urbana. J Pediatr. 2012; 88(4):328-334.

12. Cruz Neto O. O trabalho de campo como descoberta e criação. In: Minayo MCS. Pesquisa social: teoria, método e criatividade. 16. ed. Petrópolis: Vozes; 1993. 
13. Minayo MCS. O desafio do conhecimento: pesquisa qualitativa em saúde. 10. ed. São Paulo: Hucitec; 2007.

14. Bardin L. Análise de conteúdo. São Paulo: Edições 70; 2011. 229 p.

15. Story M, Kaphingst KM, Robinson-O’Brien R, Glanz K. Creating healthy food and eating environments: policy and environmental approaches. Annual Rev Public Health 2008; 29:253-272.

16. Swinburn B, Egger G, Raza F. Dissecting obesogenic environments: the development and application of a framework for identifying and prioritizing environmental interventions for obesity. Prev Med. 1999; 29 (6 pt 1):563-570.

17. Pollan M. Em defesa da comida: um manifesto. Rio de Janeiro: Intrínseca; 2008. 272 p.

18. Brasil. Ministério da Saúde. Guia alimentar para a população brasileira. 2. ed. Brasília: Ministério da Saúde; 2014. 158 p.

19. Feitosa EPS, Dantas CAO, Andrade-Wartha ERS, Marcellini PS, Mendes-Netto RS. Hábitos alimentares de estudantes de uma universidade pública no nordeste, Brasil. Alim Nutr. 2010; 21(2):225-230.

20. Fonseca AB, Souza TSN, Frozi DS, Pereira RA. Modernidade alimentar e consumo de alimentos: contribuições sócio-antropológicas para a pesquisa em nutrição. Ciênc Saúde Coletiva 2011; 16(9):3853-3862.

21. Fitzgerald N, Spaccarotella K. Barriers to a healthy lifestyle: from individuals to public policy: an ecological perspective. Journal of Extension 2009; 47(1):1-8.

22. Castro IRR, Castro LMC, Gugelmin SA. Ações educativas, programas e políticas envolvidos nas mudanças alimentares. In: Diez-Garcia RW, Cervato-Mancuso AM. Mudanças alimentares e educação nutricional. Rio de Janeiro: Guanabara Koogan; 2012. p. 18-34.

23. Simão CB, Nahas MV, Oliveira ESA. Atividade física habitual, hábitos alimentares e prevalência de sobrepeso e obesidade em universitários da Universidade do Planalto Catarinense - UNIPLAC, Lages/SC. Rev Bras Ativ Fís Saúde 2006; 11(1):3-12.

24. Marcondelli P, Costa THM, Schmitz BA. Nível de atividade física e hábitos alimentares de universitários do $3^{\circ}$ ao $5^{\circ}$ semestres da área da saúde. Rev Nutr. 2008; 21(1):39-47.

25. Ramalho AA, Dalamaria T, Souza OF. Consumo regular de frutas e hortaliças por estudantes universitários em Rio Branco, Acre, Brasil: prevalência e fatores associados. Cad Saúde Pública 2012; 28(7):1405-1413.

26. Alves HJ, Boog MCF. Promoção de saúde e comensalidade: um estudo entre residentes de moradia universitária. Revista de Segurança Alimentar e Nutricional 2006; 13(2):43-53.

27. Batalha MO, Luchese T, Lambert JL. Hábitos de consumo alimentar no Brasil: realidade e perspectivas. In: Batalha MO. Gestão de agronegócios: textos selecionados. São Carlos: Editora UFSCar; 2005.

Recebido: 30/12/2016

Revisado: 29/03/2017

Aceito: 15/05/2017 
